\title{
Autophagy in the endocrine glands
}

\section{Andrea Weckman, Antonio Di leva, Fabio Rotondo', Luis V Syro², Leon D Ortiz Kalman Kovacs ${ }^{1}$ and Michael D Cusimano}

Division of Neurosurgery, Department of Surgery, St Michael's Hospital, University of Toronto, Toronto, Ontario, Canada

${ }^{1}$ Division of Pathology, Department of Laboratory Medicine, St Michael's Hospital, University of Toronto, Toronto, Ontario, Canada

${ }^{2}$ Department of Neurosurgery, Hospital Pablo Tobon Uribe and Clinica Medellin, Medellin, Colombia

${ }^{3}$ Division of Neurooncology, Instituto de Cancerologia, Clinic Las Americas, Medellin, Colombia
Correspondence should be addressed to A Di leva

Email

diieva@hotmail.com

\begin{abstract}
Autophagy is an important cellular process involving the degradation of intracellular components. Its regulation is complex and while there are many methods available, there is currently no single effective way of detecting and monitoring autophagy. It has several cellular functions that are conserved throughout the body, as well as a variety of different physiological roles depending on the context of its occurrence in the body. Autophagy is also involved in the pathology of a wide range of diseases. Within the endocrine system, autophagy has both its traditional conserved functions and specific functions. In the endocrine glands, autophagy plays a critical role in controlling intracellular hormone levels. In peptide-secreting cells of glands such as the pituitary gland, crinophagy, a specific form of autophagy, targets the secretory granules to control the levels of stored hormone. In steroid-secreting cells of glands such as the testes and adrenal gland, autophagy targets the steroid-producing organelles. The dysregulation of autophagy in the endocrine glands leads to several different endocrine diseases such as diabetes and infertility. This review aims to clarify the known roles of autophagy in the physiology of the endocrine system, as well as in various endocrine diseases.
\end{abstract}

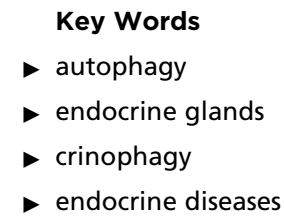

Journal of Molecular Endocrinology (2014) 52, R151-R163

\section{Introduction}

Autophagy, self-eating, or self-cannabalism is a genetically programmed and evolutionarily conserved intracellular catabolic pathway. The word 'autophagy' derives from the Greek 'auto', meaning oneself, and 'phagy', to eat (Levine \& Klionsky 2004). Under normal physiological conditions, autophagy aims to maintain cellular homeostasis via the degradation and recycling of long-lived or damaged proteins and organelles. The three main types of autophagy, macroautophagy, microautophagy and chaperone-mediated autophagy (Fig. 1), have different functions and proceed by means of different mechanisms, with the common end result of lysosomal degradation (Klionsky 2005). There are also various specific forms of autophagy, such as crinophagy, lipophagy, mitophagy and zymophagy among others (Fig. 1), which involve the deliberate degradation of specific substrates. Unless otherwise indicated, from this point forward, the term autophagy will be indicative of macroautophagy. Although the existence of autophagy was discovered many years ago, it only recently became a rapidly growing area of research. Along with its basal physiological roles, autophagy is crucially involved in the development and advancement of various diseases such as neurodegeneration, cardiac, pulmonary, muscle and liver diseases, infection, immunity and cancer (Levine \& Kroemer 2008, Mizushima et al. 2008, Choi et al. 2013). Although a large

Published by Bioscientifica Ltd. 


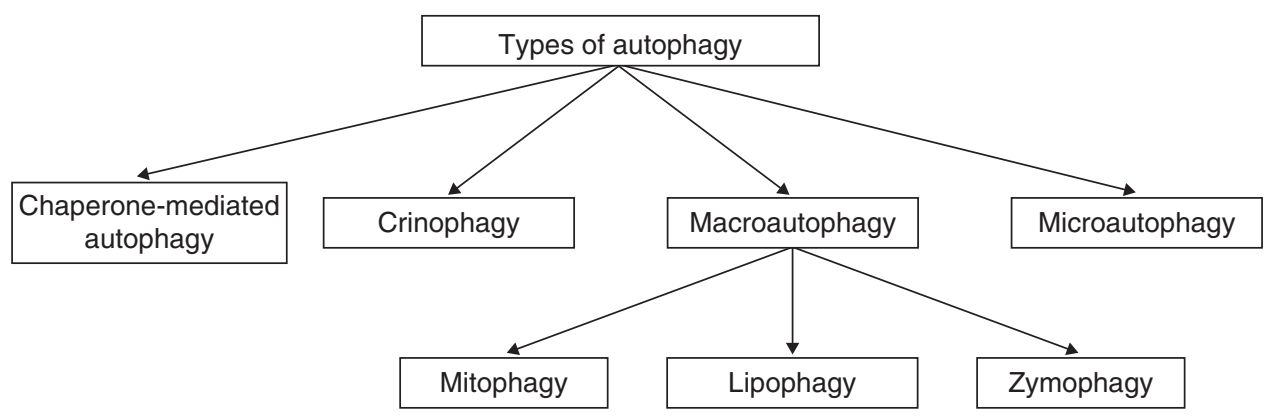

Figure 1

Schema of types of autophagy.

amount of research has been done on autophagy, in both physiological and pathological states of the endocrine system, it has never been consolidated. The present paper reviews the function and regulation of autophagy, and its role in the activity of the endocrine glands.

\section{Autophagy: regulation and function}

The term autophagy denotes the degradation of various cytoplasmic components via lysosomal delivery. Cytoplasmic components include long-lived or damaged organelles and macromolecules, intracellular pathogens and, acting alongside the ubiquitin-proteosome system, build-ups of protein aggregates (Mathew et al. 2007). Autophagy involves several steps beginning with induction - it is most commonly triggered by nutrient deprivation (Mizushima 2007) - and continuing with the engulfment of the aforementioned cytoplasmic constituents by a double-membraned phagophore or isolation membrane to form an autophagosome. The autophagosome then fuses with the lysosome, exposing its contents to lysosomal degradation. The products of this breakdown are recycled and reused as nutrients to help the cell to survive. There are already extensive reviews that explore each of these steps in detail (Levine $\&$ Klionsky 2004, Klionsky 2005, Mizushima 2007). The relatively recent discovery of 31 autophagy-related (ATG) genes in yeast, and the subsequent discovery that many are evolutionarily conserved between yeast and higher eukaryotes such as mammals, has led to huge advancements in the detailed understanding of the molecular machinery and mechanisms involved in mammalian autophagy (Yang \& Klionsky 2009).

The 'core' Atg proteins have been divided into various subgroups: the ULK protein complexes, the class III PI3-K/Vps34 complex, the Atg9/mAtg9-WIPI-1 transmembrane protein complex and the Atg12 and light chain 3 (LC3) conjugation systems (Yang \& Klionsky 2009, Tanida 2011). Even this 'core' set is composed of several different groups within each subgroup, revealing a complex system of regulation in which each component plays a different role vital to the proper functioning of autophagy as a whole. All of these proteins act downstream of mammalian target of rapamycin (mTOR) kinase, the master negative regulator of autophagy, which is itself regulated by the stimulation of the class 1 PI3-K complex by extracellular activation of growth factor receptors. Autophagy is also regulated by AMP-activated protein kinase (AMPK) which reacts to energy stress (low energy), nuclear and cytosolic p53 tumour suppressor proteins, which respond to oncogenic or genotoxic stress, the Bcl2 protein family, eIF2alpha, which is activated under conditions of nutrient deprivation and endoplasmic reticulum (ER) stress, the Ras pathway and several other modulators (Tallóczy et al. 2002, Codogno \& Meijer 2005, Klionsky 2005, Levine \& Kroemer 2008, Yang \& Klionsky 2010, Yang et al. 2011). When the cell has sufficient nutrients, mTOR kinase inhibits the ULK1 protein complex, thereby suppressing autophagy. Under conditions of nutrient starvation, mTOR kinase is inactivated, disinhibiting ULK1 and activating the intricate, multi-step process of autophagy (Yang \& Klionsky 2010). Although the molecular players in mammalian autophagy are slowly being clarified and confirmed, there is still much to be discovered. A complete understanding of the external and internal signalling regulation, as well as the downstream effectors that are involved in the process of autophagy, has important implications for the development of future therapeutic interventions in a variety of pathological conditions.

Autophagy has numerous physiological functions. During periods of metabolic stress, such as nutrient deprivation, hypoxic conditions and/or lack of growth factors, autophagy degrades proteins to provide the amino acids necessary for survival. These amino acids are used to

Published by Bioscientifica Ltd. 
synthesise proteins critical for cell adaptation to stress. They can also be used by the tricarboxylic acid cycle (TCA) to produce ATP for cellular energy (Mizushima 2007, Levine \& Kroemer 2008). Autophagy also serves as a type of quality control mechanism, clearing the cell of damaged or very old proteins and organelles, protein aggregates and foreign pathogens (Levine \& Kroemer 2008). Recently, it has been proposed that autophagy acts as a 'guardian of the genome' (Levine \& Kroemer 2008), preventing genomic instability and DNA mutations that eventually lead to tumour development (Mathew et al. 2007). Along with its basal physiological level of action, autophagy is involved in specific processes such as ageing, where it is proposed to have a potential anti-ageing effect, cellular differentiation and various aspects of developmental progression (Levine \& Klionsky 2004).

Focus on autophagy in physiology and pathology has rapidly increased because it became apparent that there are many diseases in which autophagy probably plays an important pathogenic role (Levine \& Kroemer 2008, Mizushima et al. 2008, Ravikumar et al. 2010, Choi et al. 2013). Clarifying the pathways and mechanisms of autophagy under normal conditions is essential to explaining its dysregulation in the development of disease. Moreover, to uncover the exact mechanisms and pathways of autophagy under normal conditions in a specific system, first requires knowledge of where and in what capacity autophagy is acting within that system. Thus, the present paper aims to provide the foundation for understanding the complete picture of autophagy in the endocrine glands (Table 1). Autophagy has been implicated in endocrine conditions such as infertility, and endocrine diseases such as diabetes. Providing a basis for the involvement of autophagy in the normal endocrine system and under pathological conditions is the first step in elucidating its specific mechanisms and pathways in the system. Ultimately, a more systematic approach to our understanding of autophagy in the endocrine system will enable efficient development of novel therapies for various endocrine diseases.

\section{Methods of monitoring autophagy}

The reliable assessment and study of a phenomenon are only as good as the techniques used to detect and monitor it. Thus, in order to fully consider the impact of autophagy research, the various techniques for its detection must be briefly discussed. Although there have been several recent comprehensive reviews on the topic (Mizushima et al. 2010, Klionsky et al. 2012), the proper detection and monitoring of autophagy, a highly dynamic process, remains a challenge in the field. An important distinction must be made between the measurement of number and volume of autophagic components at a certain point in the process, vs the measurement of autophagic flux. The former represents a static quantification of a dynamic process. For example, the number of autophagosomes is often used as a direct quantification of autophagic activity. It is possible, however, that a build-up of autophagosomes, instead of representing an increase in autophagic activity, could represent a blockage of their fusion with lysosomes, and thus an inhibition of autophagic activity as a whole. Thus, purely monitoring autophagosomes cannot be used as a reliable indicator of autophagic activity. The latter, which involves monitoring the progression of autophagy from autophagosome formation through to lysosomal degradation, represents a dynamic measurement of a dynamic process and as such provides more precise information on the true state of autophagic activity.

The most long-established method of detecting autophagy uses the electron microscope to ultrastructurally detect the presence of autophagic structures in both selective and non-selective autophagy. Electron microscopy remains one of the most widely used techniques for autophagy detection. It is, however, particularly vulnerable to misinterpretation and bias, and its use in concert with other methods has been strongly recommended (Klionsky et al. 2012). Fluorescence microscopy is another approach that is often applied to assess autophagic activity. Microtubule-associated protein LC3 is the only known mammalian autophagosome marker (Mizushima et al. 2010) and it exists within the cell in a cytosolic form (LC3-I), which is converted into an autophagosomal membrane-bound form (LC3-II) upon induction of autophagy. As LC3-II is concentrated on the autophagosome membrane, counting the number of GFP-LC3 punctae per cell is a common means of quantifying autophagosomes in vivo (Mizushima et al. 2010, Tanida 2011, Klionsky et al. 2012). A third method of measuring autophagic activation involves the separation and quantification of relative levels of LC3-I and LC3-II via western blot. Immunodetection of other ATG proteins (i.e. BECN1) has also been used as a general indicator of autophagy in the prognosis of various human cancers; however, more research is necessary to establish a solid correlation between immunodetection of ATG proteins and autophagic activity (Klionsky et al. 2012). Generally, static quantification of LC3 has been deemed to be a useful marker for autophagy; however, these

Published by Bioscientifica Ltd. 
Table 1 Overview of autophagy in endocrine glands

\section{Gland}

Pituitary

Testes

Adrenal

Thyroid and parathyroid

\section{Autophagy $^{\mathrm{a}}$ function as currently known}

Location: both crinophagy and macroautophagy demonstrated in all secretory cell types of the anterior pituitary Role: crinophagy is both a mechanism for normal turnover of secretory material and a means to deal with production of excess secretory material

Regulates/maintains proper intracellular levels of secretory protein

Control: suggested modulation of crinophagy by steroids

Role: macroautophagy appears to be responsible for the turnover of peptide-synthesising machinery (ER, ribosomes) rather than secretory granules

Note: lack of recent research; mechanism and role remains poorly understood

Location: macroautophagy demonstrated in ovaries of various mammals including humans

Role: required for germ cell survival during ovary development, involved also in granulosa cell survival and cell death, follicular atresia and $\mathrm{CL}$ regression

Control: oxLDL-dependent LOX1 autophagic activation in follicular atresia also induced by nutrient deprivation and cigarette smoke in animal models

Note: thought that macroautophagy may be involved in both obesity-related infertility and age-related infertility Location: macroautophagy demonstrated in rat Leydig cells, role not known in human testes

Role: steroid-producing organelles (mitochondria, smooth endoplasmic reticulum) targeted in autophagosomes, implying that macroautophagy plays a role in regulation of steroid production in Leydig cells

Control: in Leydig cells, rate of macroautophagic activity fluctuates in tandem with steroid secretion (increased in inhibited cells and vice versa)

Note: macroautophagic deficiency implicated in reduction of testosterone production in aged rat Leydig cells

Location: macroautophagy demonstrated in both adrenal medulla and adrenal cortex

Role: macroautophagic activity demonstrated in adrenal medulla cells; however, no publications on role; possible role of crinophagy similar to that of other peptide-secreting endocrine cells

Role: macroautophagy in adrenal cortical cells same role as in Leydig cells (control of intracellular steroid levels via organelle degradation)

Thyroid: limited data on autophagy in thyroid gland under physiological or non-cancerous pathological conditions

Thyroid hormone levels do not appear to be regulated by autophagy

Note: secretory granules containing calcitonin in parafollicular cells of thyroid may be regulated by crinophagy similarly to other endocrine cells

Parathyroid: in bovine parathyroid, crinophagy functions to eliminate excess hormone; no human data

Pancreas Location: both macroautophagy and crinophagy demonstrated in pancreatic islet B-cells; endocrine organ most extensively studied in terms of autophagy

Role: levels of B-granules storing insulin are kept constant by crinophagy; correlation between rates of insulin synthesis and secretion and rate of crinophagy

Crinophagy activated in islets during periods of hormone overproduction or suppression of hormone secretion; thus, regulates secretory granule levels

Control: corticosterone and progesterone activity on glucocorticoid receptors modulates crinophagy in pancreatic islets; prostaglandin level may also be involved in crinophagy regulation

Role: macroautophagy protects B-cells from ER and oxidative stress by eliminating protein aggregates and digesting damaged mitochondria

Note: Deficient macroautophagy is thought to play a major role in pathophysiology of type 2 diabetes

N.B. macroautophagy vs crinophagy: 1) both macroautophagy and crinophagy appear to regulate intracellular hormone levels in the endocrine system via different mechanisms - the former via degradation of hormone-producing machinery, the latter via direct fusion of secretory granules with lysosomes; 2) as steroids are not stored in secretory granules, in steroid-secreting endocrine cells, crinophagy does not exist and macroautophagy is the predominant control mechanism of intracellular hormone levels.

a Here, autophagy refers to autophagy in general; crinophagy and macroautophagy are differentiated within the table.

methods are not perfect and each has specific caveats required to maximise accuracy and reliability.

LC3 is also useful in autophagic flux assays. As LC3-II itself is degraded in autolysosomes, monitoring LC3-II turnover gives an idea of autophagic flux. This is accomplished by using western blot to compare the amounts of LC3-II in the presence or absence of a lysosomal inhibitor. The difference in the amounts of LC3-II represents the amount that has been degraded and thus the autophagic flux. Furthermore, as total LC3 within the cell is ultimately reduced during prolonged autophagy, the observed decrease in LC3 is inversely correlated to autophagic flux and can be measured using flow cytometry or fluorescence microscopy (Mizushima et al. 2010). Other cellular components that are selectively taken up by autophagosomes for degradation, such as p62 (Bjørkøy et al. 2005), can be monitored in a similar manner. An mRFP-GFP-LC3 construct takes advantage of the fact that GFP loses its fluorescence in the low $\mathrm{pH}$ of the lysosome to depict autophagic flux (Kimura et al. 2007, http://jme.endocrinology-journals.org DOI: 10.1530/JME-13-0241
() 2014 Society for Endocrinology Printed in Great Britain
Published by Bioscientifica Ltd. 
Mizushima et al. 2010, Klionsky et al. 2012). In the cytosol or anchored to autophagosomes, LC3 will fluoresce yellow. Autolysosomes containing LC3, however, will be labelled red, as GFP is quenched. Thus, the progression from autophagosome formation to its fusion with a lysosome can be monitored using this tandem construct.

The classic technique to monitor autophagic flux involves the measurement of long-lived protein degradation. Incubating cells with radiolabelled amino acids followed by a shorter incubation without radiolabelled amino acids allows for the proteosomal degradation of labelled short-lived proteins and results in only long-lived proteins with radioactive labels. As long-lived proteins are predominantly degraded via autophagy, the release of acid-soluble radioactivity resulting from the degradation of the proteins is measured to indicate autophagic flux. To account for any non-autophagic degradation of radiolabelled proteins, the results are compared with those from a condition in which an autophagic inhibitor is applied to the culture (Mizushima et al. 2010, Klionsky et al. 2012).

This brief summary of several techniques for detecting and monitoring autophagy represents only the most common methods. A more comprehensive look at the existing techniques and their limitations has been described in detail elsewhere (Mizushima et al. 2010, Klionsky et al. 2012). It must be emphasised that each technique has its limitations and the strongest and most reliable experimental approaches are ones that use several techniques to create a multi-faceted assessment of autophagy.

\section{Autophagy in the endocrine glands}

\section{Crinophagy}

Crinophagy, discovered in pituitary mammotrophs by Smith \& Farquhar (1966), and so named by Christian de Duve (1969), derives from the Greek word 'crin', which means 'to secrete' (Klionsky et al. 2007). It describes the process whereby secretory granules containing cellspecific proteins for secretion from endocrine glands fuse directly with lysosomes for degradation (de Duve 1969). It should be noted that as steroids are not stored in granules, crinophagy does not occur in steroid-secreting cells of the endocrine glands. There is a notable functional/structural difference between the elimination of secretory granules by crinophagy and by macroautophagy. Whereas autophagy engulfs the secretory granule in its entirety and delivers it, along with many other cellular components, to the lysosome for degradation, the direct fusion of secretory granule to lysosome (crinophagy) presumably spares the granule membrane from degradation and allows it to be recycled (Smith \& Farquhar 1966, Marsh et al. 2007). Thus, crinophagy appears to be a more energy efficient method of autophagy for the specific regulation of normal fluctuations in secretory material. The most common method of crinophagic detection was, and currently remains, electron microscopy. Evidence of crinophagy has been uncovered in most of the endocrine glands, and is generally accepted as the main way that peptide-secreting endocrine cells degrade excess secretory material (Marzella et al. 1981). It has been established that crinophagy is upregulated in response to an inhibition of secretion or an overproduction of secretory material, but the mechanism of induction and regulation remains largely unknown. Modulation by steroids has been suggested in the pituitary, where oestrogen positively and progesterone negatively correlated with crinophagy of prolactin secretory granules (Poole et al. 1981, Kuriakose et al. 1989), and the pancreas, where progesterone upregulated and corticosterone downregulated crinophagy in B-cells (Sandberg \& Borg 2007). As progesterone had an opposite effect on crinophagy in the pituitary compared with the pancreatic islets, there appears to be no universal relationship between progesterone and crinophagy. In the pancreatic islet B-cells, changes in crinophagy levels due to progesterone and corticosterone were blocked with mifepristone, a receptor antagonist for both corticosterone and progesterone receptors (Sandberg \& Borg 2007). Furthermore, crinophagy levels positively correlated with increased production of prostaglandin $\mathrm{E}_{2}$ via progesterone stimulation and its decreased production via corticosterone stimulation. This suggests that in pancreatic B-cells, corticosterone and progesterone stimulation may directly modulate crinophagy through their regulation of prostaglandin $\mathrm{E}_{2}$ (Sandberg \& Borg 2007). In the pituitary, however, where oestrogen is known to induce the synthesis and secretion of prolactin, the correlation between oestrogen and crinophagy may be an indirect one; the increase in crinophagy triggered by the overproduction of prolactin rather than by oestrogen stimulation directly (Kuriakose et al. 1989). More research is required to confirm the mechanism(s) of steroid-dependent crinophagy modulation. Inhibition of negative regulators has also been suggested as a method of inducing crinophagy and autophagy when hormone secretion is inhibited. In secretory-deficient pancreatic B-cells, LAMP2, a negative regulator of autophagy, was significantly downregulated

Published by Bioscientifica Ltd. 
in cells in which crinophagy and autophagy had been upregulated (Marsh et al. 2007). This suggests that the inability to secrete hormones somehow activates an intracellular signalling cascade that induces crinophagy and autophagic degradation of secretory granules. Regardless of the mechanism and whether the initiating event is specific to each cell type, as many other aspects of crinophagy are conserved between endocrine cells, it is likely that the final downstream effectors are the same in all peptide-secreting cells. In the remainder of this section, the presently known specifics of crinophagy (and autophagy) in the context of each endocrine gland will be described.

\section{Pituitary gland}

The discovery of autophagy, and more specifically, crinophagy, in the anterior pituitary gland began with the investigation of mammotrophs, lactotrophs or prolactin-secreting cells of the hypophysis. In secretory cells such as those of the anterior pituitary, crinophagy functions as both a normal physiological mechanism for the regular turnover of secretory material, as well as a means of dealing with the induced production of excess secretory material. During the natural oestrous cycle of the rat, if pregnancy does not occur and prolactin is not required, the excess prolactin granules fuse with lysosomes to be degraded and their amino acid components to be recycled (Poole et al. 1981). During lactation, mammotrophs increase the synthesis and secretion of prolactin, which decreases after weaning, while crinophagic bodies degrading excess prolactin-filled secretory granules increase after weaning (Bernabé et al. 2001). Crinophagy can also be induced. After premature removal of suckling young from lactating mother rats, the secretory activity of mammotrophs is inhibited, and the resulting excess secretory granules are eliminated via crinophagy (Smith \& Farquhar 1966). Although research regarding crinophagy in the pituitary gland has predominantly focused on mammotrophs, crinophagy has also been confirmed in other cell types of the rat pituitary such as corticotroph, somatotroph, gonadotroph and thyrotroph cells (Farquhar 1969, Sirek et al. 1976, Moi et al. 1984). Moi et al. (1984) discovered that crinophagy increased in the corticotrophs during states of both hypersecretion due to adrenalectomy and hyposecretion induced by administration of dexamethasone. Thus, in the pituitary gland, crinophagy acts in tandem with natural and induced fluctuations in secretory activity to continuously regulate and maintain proper intracellular levels of secretory protein (Smith \& Farquhar 1966, Farquhar 1977).
Although the complete mechanism and regulation of crinophagy in the pituitary gland remains poorly understood, as discussed above, several studies have correlated rates of crinophagy in mammotrophs to levels of steroid hormones such as oestradiol or progesterone, whereby oestrogen seems to induce crinophagy and progesterone seems to decrease it, indicating that crinophagy in the pituitary gland may be modulated by steroids (Poole et al. 1981, Kuriakose et al. 1989).

In addition to the direct fusion of secretory granules with lysosomes (i.e. crinophagy), autophagic vacuoles encompassing protein-synthesising machinery such as rough ER and ribosomes, but rarely secretory granules, were also found in mammotrophs of the anterior pituitary gland (Smith \& Farquhar 1966). Thus, it seems that the autophagic system accounts mainly for the turnover of secretory protein synthesising machinery, rather than the secretory granules themselves (Farquhar 1971). After adrenalectomy, hypersecretion from corticotrophs caused a corresponding increase in autophagy of non-granule cellular constituents, establishing a logical link between high rates of secretory activity and increased rates of organelle turnover (Moi et al. 1984). Although the volume of mammotrophic autophagic vacuoles fluctuated with the natural oestrous cycle of the rat, remaining low during the proestrous phase, beginning to rise in early oestrous and peaking near the end of the oestrous phase (Poole et al. 1981), it was mostly crinophagy that controlled standard secretory granule levels. Within the oestrous cycle, autophagic vacuoles increased as the surface area of the rough ER and Golgi apparatus decreased, further supporting the proposition that autophagy is mostly involved with controlling hormone synthesising machinery rather than secretory granule levels (Poole et al. 1981). In addition, autophagy was found to be most active during externally induced cellular involution in the mammary gland (Smith \& Farquhar 1966).

The lack of recent research is a severe limitation to our understanding of autophagy in the pituitary gland. With modern tools and techniques, the precise role and mechanisms of regulation of autophagy and crinophagy in the pituitary could be more thoroughly elucidated. This lack of research most likely stems from a lack of demand for increased knowledge concerning autophagy in the pituitary gland. As with all scientific endeavours; however, it must be considered that there remain untouched roles for autophagy in the normal pituitary, or in its pathologies, that could be revealed using modern technology. These discoveries could help to explain the pathophysiology of pituitary diseases such as hypo- and

Published by Bioscientifica Ltd. 
hyperpituitarism, or even provide a better understanding of autophagy that could be translatable to other human endocrine glands and tissues.

\section{Ovaries and testes}

The discovery of autophagy in the ovaries of a wide range of animals including Drosophila, fish, quail, nonhuman primates, mice and other small mammals, suggests a highly conserved role of autophagy in various ovarian processes, such as follicular atresia and corpus luteum (CL) regression. Autophagy is also an important mechanism in human physiological ovarian function. During development, before the formation of the primordial follicle pool, autophagy appears to be required for germ cell survival (Gawriluk et al. 2011). Later, in each menstrual cycle, ovarian follicles not chosen as the preovulatory follicle undergo follicular atresia. Originally, follicular atresia was thought to occur entirely by apoptosis. The discovery of granulosa cell death via oxidised LDL (oxLDL)-dependent lectin-type oxLDL receptor (LOX1)-activated autophagy, however, suggests that autophagic forms of programmed cell death are also involved (Duerrschmidt et al. 2006, Serke et al. 2009). As obese women have increased levels of oxLDL (Mutlu-Türkoğlu et al. 2003), and consequently a higher incidence of autophagic granulosa cell death, this pathway could account for a higher rate of infertility in obese women (Duerrschmidt et al. 2006). LOX1 stimulation by oxLDL has also been associated with an increased level of reactive oxygen species (ROS) leading to oxidative stress and apoptotic cell death. In younger, normal weight women, reparative autophagy is induced in response to low levels of ROS in order to avoid apoptosis and promote cell survival (Vilser et al. 2010). An increase in ROS levels, as well as a decline in autophagic markers (LC3-II) in human granulosa cells of older women suggests that there is a decline in reparative autophagy with age leading to granulosa cell apoptosis (Tatone et al. 2006, Vilser et al. 2010). This result is in concordance with the well-documented, age-related decline in female fertility (Carbone et al. 2003, Tatone et al. 2006, 2008).

Various other factors, such as nutrient deprivation and, more recently, cigarette smoke, have also been shown to induce autophagic programmed cell death in granulosa cells of animal models (Gannon et al. 2013). These findings offer a promising explanation for the reported correlation between smoking and infertility in female humans (Gannon et al. 2013).

After ovulation, a progesterone-producing endocrine organ, the $\mathrm{CL}$, is formed in the ovary. Without pregnancy, the CL regresses at the end of the menstrual cycle. Electron microscopic studies revealed the presence of autophagosomes in many cells during CL regression (Del Canto et al. 2007). At the molecular level, there is a specific endocrine voltage-activated sodium channel in the human ovary from which downstream signalling induces autophagy in CL regression (Bulling et al. 2000). Conversely, there is increased beclin-1 expression in CL cells during pregnancy as well as in pathological conditions when the CL survives longer than normal, implicating autophagy in granulosa cell survival as well (Gaytán et al. 2008). True to the double-edged reputation of autophagy, these findings suggest opposing roles for autophagy in CL dynamics. This collection of animal and human studies provides convincing evidence for the occurrence and importance of autophagy in ovarian function.

To our knowledge, there are no English-language papers exploring the role of autophagy in the human testes. In rats, however, autophagy occurs more in normally functioning, testosterone-secreting Leydig cells than in many other cell types (Tang 1988). In Leydig cells, autophagosomes preferentially sequester steroidproducing organelles such as mitochondria and smooth ER, implying that autophagy has a role in the process of steroid production. Furthermore, the rate of autophagic activity fluctuates in tandem with steroid secretion autophagy is increased in inhibited cells and decreased in stimulated cells (Yi \& Tang 1995). This pattern of activation and inhibition of autophagy closely resembles that of crinophagy in the peptide-secreting cells of the pituitary. As steroids are not stored in secretory granules within the cells, steroid-secreting cells deal with excess secretory material via degradation of steroid-producing organelles (Yi \& Tang 1995). Thus, in rat Leydig cells, traditional autophagy appears to be involved in the regulation of steroid secretion in a manner analogous to crinophagy in peptide-secreting endocrine cells. This process is most likely upheld in steroid-producing cells of the ovary and adrenal gland as well.

Autophagic deficiency was also recently implicated in the reduction of testosterone production in aged rat Leydig cells. It is generally established that autophagy decreases with age (Cuervo et al. 2005, Mizushima et al. 2008). In the case of aged Leydig cells, decreased autophagy, particularly mitophagy or the selective degradation of damaged mitochondria, leads to a decrease in the clearance of dysfunctional mitochondria and consequently, an accumulation of ROS. As ROS are detrimental to Leydig cell steroidogenesis (Zirkin \& Chen 2000, Diemer et al. 2003), this accumulation leads to a decrease in testosterone

Published by Bioscientifica Ltd. 
levels, ultimately resulting in conditions such as late-onset hypogonadism (Li et al. 2011).

There is evidence of autophagy in Sertoli cells of rat testes, as well. Increased mitochondrial-mediated germ cell apoptosis has been observed in ethanol-treated rats (Eid et al. 2002). Electron microscopy and immunohistochemistry of autophagy genes (i.e. Lc3) also exposed the presence of autophagy in the Sertoli cells of ethanolexposed rats. Of most importance was the discovery of increased mitophagy, leading to the hypothesis that mitophagy may be acting in an anti-apoptotic capacity against ethanol toxicity in Sertoli cells by clearing damaged mitochondria and preventing their release of pro-apoptotic factors (Eid et al. 2012).

The collection of research investigating autophagy in the ovaries and testes of humans and animals reveals, not surprisingly, a diverse set of confirmed and proposed functions for autophagy within the reproductive system. The relative lack of human data, however, leaves the impression that much remains to be discovered.

\section{Adrenal gland}

In the adrenal medulla, adrenaline and noradrenaline are stored in secretory granules similar to those of other peptide-secreting endocrine cells, and a cytochemical study of adrenal medulla cells revealed evidence of autophagy within those cells (Holtzman \& Dominitz 1968, Trifaro 1977). Although to our knowledge no recent research has been published on autophagy in the adrenal medulla, it is highly probable that the roles of crinophagy and autophagy in other peptide-secreting endocrine cells are translatable to the secretory cells of the adrenal medulla.

As the adrenal cortex is composed of steroid-secreting cells similar to Leydig cells of the testes, it is likely that autophagy has a comparable function in both. In fact, a study looking at both Leydig and adrenocortical fasciculata cells in rats showed that autophagy in steroidsecreting cells plays a hormone-producing modulatory role similar to that of crinophagy in peptide-secreting endocrine cells (Yi \& Tang 1995). In addition, there is a unique role for autophagy in the growth regulation of parenchymal cells in the adrenal zona fasciculate (Müller et al. 1987). By measuring autophagic vacuole fractional volume in adrenocortical zona fasciculata cells in rats exposed to adrenocorticotropic hormone (ACTH), Müller et al. (1987) showed that autophagy was strongly inhibited during ACTH-induced hyperplasia. This finding, along with the discovery of the same phenomenon in the regenerating liver (Pfeifer 1979), suggested that inhibiting autophagic degradation is a pro-growth mechanism in fast-growing organs such as the regenerating liver and ACTH-stimulated adrenal cortex (Müller et al. 1987).

A more recent study has mentioned that $\operatorname{Atg} 5^{-/-}$mice exhibited ubiquitin-positive protein aggregate formation in the liver, the anterior pituitary lobe and the adrenal cortex (Hara et al. 2006). In contrast, only a small number of protein aggregates were displayed in the skeletal muscle and the heart (Mizushima \& Hara 2006). This data seems to stress the importance of autophagy in the endocrine glands in particular. Perhaps the increased incidence of misfolded and aggregated proteins in autophagy-deficient endocrine cells such as pituitary and adrenocortical cells is a direct consequence of their increased rate of hormone production and turnover. The connection between increased vulnerability to toxic protein aggregation in endocrine cells and autophagy certainly merits further research, with the potential for shedding light on underlying mechanisms in endocrine diseases.

\section{Thyroid and parathyroid glands}

Very little research has been performed regarding autophagy in the thyroid gland under physiological or noncancerous pathological conditions. Although the thyroid hormone precursor thyroglobulin is proteolytically cleaved into the active thyroid hormones tri-iodothyronine $\left(\mathrm{T}_{3}\right)$ and thyroxine $\left(\mathrm{T}_{4}\right)$ by lysosomes, it is stored in the extracellular follicular colloid, rather than in intracellular granules (Yen 2001). Thus, thyroid hormone levels do not appear to be regulated by crinophagy or autophagy. It is likely, however, that secretory granules containing calcitonin in the parafollicular cells of the thyroid gland are regulated by crinophagy in a similar fashion to the majority of endocrine cells.

Recently, it was discovered that thyroid hormones, in particular $\mathrm{T}_{3}$, induce autophagy in in vitro human liver cells and in vivo mouse liver cells (Sinha et al. 2012). In particular, $\mathrm{T}_{3}$ induces selective autophagy of lipids, otherwise called lipophagy, an important mechanism for lipid homeostasis, metabolism and mobilisation of lipids in hepatic cells (Sinha et al. 2012).

Similarly, there is very little to be found about autophagy in the parathyroid gland. In the bovine parathyroid gland, crinophagy occurs in response to the suppression of parathyroid hormone secretion; in this case, secretion is suppressed by high concentrations of $\mathrm{Ca}^{2+}$ (Chertow et al. 1975, Habener et al. 1975). Crinophagy in the bovine parathyroid gland thus

Published by Bioscientifica Ltd. 
functions as a means to eliminate excess hormone, analogous to the mechanism in other endocrine cells.

\section{Pancreatic islets}

Autophagy in the endocrine system has been most extensively studied in the pancreas. Pancreatic B-cells are the sole source of insulin in circulation and, as such, are critical for the regulation of blood glucose levels (Hartley et al. 2009). Elevated glucose levels stimulate insulin secretion from B-cells. Insulin then acts at fat, liver and muscle cells to induce absorption of glucose from the bloodstream or to stop hepatic glucose production. As in other endocrine cells, once insulin is synthesised, it is packaged into secretory granules, termed B-granules, ready for secretion via exocytosis. As B-granules have a half-life of only 3-5 days, a basal level of crinophagy ensures that the number of B-granules stays relatively constant and the 'old' B-granules are continuously turnedover (Halban 1991). Several landmark studies investigated the relationship between glucose, B-cell stimulation and intracellular insulin degradation (Halban \& Wollheim 1980, Schnell et al. 1988). Schnell et al. (1988) noticed that at varying levels of glucose stimulation, a corresponding imbalance between rates of insulin synthesis and insulin secretion influenced the rate of crinophagy in isolated pancreatic islet cells. It was only at intermediate levels of glucose, where there was sufficient stimulation to increase insulin synthesis but not to trigger insulin secretion, that B-granules accumulated and crinophagy was upregulated (Schnell et al. 1988). Furthermore, in Rab3A ${ }^{-/-}$(secretiondeficient) mice, B-cells responded to insulin overproduction by increasing both crinophagic and autophagic degradative processes to keep B-granule levels stable (Marsh et al. 2007). Thus, similar to the rest of the endocrine system, crinophagy is activated in pancreatic islets during periods of hormone overproduction or suppression of hormone secretion, to digest and ultimately recycle excess secretory granules.

The specifics of crinophagy induction and modulation in the pancreas are complex and incompletely known. Along with the ability of glucose to modulate crinophagy levels, Sandberg \& Borg (2007) showed that corticosterone and progesterone acting on glucocorticoid receptors affected intracellular degradation of insulin, potentially by affecting the production of prostaglandins within the B-cells. This finding represents the first mention of a possible downstream molecule that could be involved in the regulation of crinophagy.
Traditional autophagy also plays its traditional role in the functioning of pancreatic B-cells by degrading and recycling macromolecules and old or damaged organelles (Landström 1987, Hartley et al. 2009). When the B-cell ER's protein-folding capabilities cannot keep up with the demands (e.g. during chronic hyperglycemia), the cell enters a state of ER stress. ER stress leads to a build-up of misfolded proteins, which, if not immediately degraded, become protein aggregates and ultimately result in cellular toxicity and apoptosis (Kaniuk et al. 2007, Hartley et al. 2009). It has been suggested that autophagy is generally required to eliminate protein aggregates, while the ubiquitin-proteasome system degrades soluble misfolded proteins that have not yet formed aggregates (Kaniuk et al. 2007, Hartley et al. 2009). Furthermore, mitochondrial dysfunction caused by stressors such as chronic hyperglycaemia induces the accumulation of ROS within the cells, resulting in oxidative stress. Autophagy protects B-cells from oxidative stress by digesting the damaged mitochondria (Twig et al. 2008). Due to the high level of protein synthesis that occurs in pancreatic B-cells, they are especially susceptible to ER and oxidative stress (Hartley et al. 2009, Jung \& Lee 2009). Autophagy plays an indispensable role in the maintenance of B-cell performance during adverse conditions.

From a pathological standpoint, type 2 diabetes is the most researched disorder involving pancreatic B-cells and autophagy. Type 2 diabetes is characterised by insulin resistance in peripheral tissues (i.e. fat, muscle, liver), as well as impaired insulin secretion resulting in chronically elevated blood glucose levels, and subsequent death of pancreatic B-cells. With the intent of uncovering a definitive role for autophagy in the pancreas, several studies have focused on a conditional (B-cell specific) knockout of Atg7, an autophagy-related gene, in the pancreatic B-cells of mice (Ebato et al. 2008, Jung et al. 2008). These mice demonstrated the hallmark dysfunctions of type 2 diabetes: defective insulin tolerance, decreased insulin blood levels (and secretion), and decreased B-cell mass due to increased cell death and decreased B-cell proliferation. In addition, Atg7-deficient mice exhibited accumulation of ubiquitinated protein aggregates and damaged organelles (i.e. mitochondria, ER), the presence of which most likely caused the increase in cell death and resulting decreased B-cell mass (Ebato et al. 2008, Jung et al. 2008). A human study of type 2 diabetic patients revealed an accumulation of autophagosomes in B-cells, most likely due to impaired removal of the autophagosomes, and a corresponding increase in B-cell death (Masini et al. 2009). Together, these findings

Published by Bioscientifica Ltd. 
implicate deficient autophagy as a major player in the pathophysiology of type 2 diabetes.

One of the proposed causes for the onset of B-cell deterioration in type 2 diabetes is diet-induced nutrient (free fatty acids (FFA), glucose or both) surplus (Las et al. 2011). For example, chronic glucose overload leads to an unsustainable increase in insulin demand, eventually resulting in toxic ER and oxidative stress within the B-cells. Chronic exposure of isolated mouse, rat and human pancreatic B-cells to FFAs also impaired insulin secretion (Zhou \& Grill 1994, Bollheimer et al. 1998, McGarry \& Dobbins 1999) and induced autophagy, especially an increase in autophagosome formation (Lupi et al. 2002, Las et al. 2011). If autophagy were dysfunctional, as hypothesised in type 2 diabetes, the build-up of misfolded proteins and ER/oxidative stress products caused by hyperglycemia and lipotoxicity would invariably lead to B-cell damage and death. As obesity, characterised by high levels of FFAs in the circulation, is the primary cause of type 2 diabetes, these findings created a strong link between glucolipotoxicity, type 2 diabetes and autophagy. Ebato et al. (2008) strengthened this connection using Atg7-deficient mice. Although control mice exposed to a high-fat, diet-induced autophagy in the pancreatic B-cells protect themselves from the FFAinduced B-cell dysfunction, oxidative stress and resulting apoptosis, Atg7-deficient mice exposed to a high-fat diet could not induce autophagy and experienced extensive B-cell death, along with other classic features of type 2 diabetes (Ebato et al. 2008). Thus, it appears that autophagic deficiency in pancreatic B-cells plays an important role in the pathogenesis of type 2 diabetes. Although various studies have suggested potential molecular mechanisms to describe the pathway surrounding the contribution of autophagy in B-cells and diabetes (Marsh et al. 2007, Grasso et al. 2009, Masini et al. 2009, Las et al. 2011), none have been definitively proven or reproduced. As more evidence concerning the general involvement of autophagic deficiency in type 2 diabetes accumulates, its precise delineation will be critical in taking advantage of the discovery. The current state of this research provides the basis for an interesting new avenue of investigation that could focus on therapeutically targeting the molecular mechanisms of pancreatic B-cell autophagy in patients with type 2 diabetes.

There has been no research focused on autophagy or crinophagy in the other endocrine cells of the pancreas (i.e. alpha, delta, gamma or epsilon cells), although Masini et al. (2009) did show that autophagy in alpha and delta cells was not affected in humans with diabetes. As they are all peptide-hormone-producing cells, it is likely that crinophagy plays the same role as in the other peptidesecreting cells discussed above.

\section{Future implications}

The topic of autophagy has garnered increasing attention with the discovery of its role in a wide range of physiopathological processes. In several glands, notably the pituitary, adrenal and thyroid glands, there is a major lack of recent research about autophagy/crinophagy, or in the former case, research at all. Although the gold standard for detecting crinophagy (i.e. electron microscopy) has not changed since its discovery (Smith \& Farquhar 1966, de Duve 1969), reassessing these glands based on recent research would most likely be enlightening. For example, understanding the basis of crinophagy as a tool to modulate intracellular hormone content, it is plausible to extrapolate that dysfunctional or overactive crinophagy may play a role in those cases of hypo- or hyper-endocrine activity that have no other visible explanation. Knowing that autophagy already has a known involvement in endocrine diseases such as type 2 diabetes and infertility is sufficient evidence to warrant renewed investigation into autophagy in the pathologies of the other endocrine glands.

For research concerning autophagy and crinophagy to progress, the detection techniques must necessarily progress as well. As autophagy has been implicated in a wide range of diseases and its potential as a therapeutic target appears extremely promising, the proper interpretation of autophagic activity is critical to our understanding of its involvement and our ability to act accordingly. Currently, the best approach to monitoring autophagy involves the use of several moderately reliable techniques (Mizushima et al. 2010, Klionsky et al. 2012). Continued research into the specific players and markers of autophagy will allow us to develop increasingly reliable detection and monitoring techniques. As autophagy has the potential to be both activated and inhibited in different stages of the same disease, being able to accurately monitor its progression is critical in maximising the potential for appropriate therapeutic intervention.

Furthermore, there is little or no information on the mechanisms and pathways that lead to the activation or inhibition of crinophagy specifically. Everything from the extracellular initiating event to the intracellular signalling cascade currently remains a black box. Thus, future research should attempt to uncover this signalling mechanism and perhaps even attempt to compare it with what is known about autophagy signalling.

Published by Bioscientifica Ltd. 
There is considerably more known about the mechanism and regulation of autophagy - our understanding is still not complete, however, and perhaps there is new information to be gained from further exploring crinophagy. Another interesting avenue of future research would be to determine how much of the crinophagic and autophagic pathways are conserved between each endocrine gland. As the overall function of both processes is conserved between the glands, it is likely that the intracellular signalling pathways downstream of the initial signalling event are also similar. Knowing which aspects of crinophagy and autophagy are conserved between glands and which aspects are specific would be important for therapeutically targeting them in gland- or even cellspecific diseases such as diabetes.

\section{Conclusion}

In addition to the traditional role for autophagy in cellular homeostasis, stress survival and general cellular 'housekeeping', there is a major theme that underlies the role of autophagy in the endocrine system specifically. In each gland, autophagy is involved in the regulation of intracellular hormone levels and thus indirectly involved in controlling hormone levels throughout the body. In peptide-secreting cells, autophagy achieves this via crinophagy or direct fusion of secretory granules with lysosomes. As steroid hormones are not stored in secretory granules, in steroid-secreting cells, autophagy targets the steroid-producing machinery (i.e. ER, mitochondria) instead. Although this function has been established in all of the endocrine glands, the pathway surrounding the process, including the upstream and downstream signals, remains a black box. Perhaps the lack of recent research concerning autophagy in the endocrine glands is a reflection of the lack of data implicating autophagy in diseases of those glands. For example, the pancreas, in which autophagy has been strongly implicated in the pathogenesis of type 2 diabetes, has received an abundance of research attention. In the rest of the endocrine system, however, autophagy has not yet been implicated in many disorders other than tumours. With increasing evidence of the involvement of autophagy in a range of diseases such as tumours, neurodegenerative, infectious, cardiovascular, metabolic and pulmonary diseases (Choi et al. 2013), it is becoming ever more clear that autophagy has an incredibly vast range of connections to proper bodily function. Thus, it is likely that autophagy does play an important role in endocrine disorders such as hypo- and hyperfunction. To develop effective therapeutics for these diseases, the precise molecular mechanisms must be elucidated. There is a large gap in current research on the topic. With modern technologies and techniques, the scientific community has much to gain from a renewed interest in the molecular mechanisms of autophagy in the endocrine system, especially under pathological conditions.

\section{Declaration of interest}

The authors declare that there is no conflict of interest that could be perceived as prejudicing the impartiality of the review.

\section{Funding}

This research did not receive any specific grant from any funding agency in the public, commercial or not-for-profit sector.

\section{Acknowledgements}

The authors are grateful to the Jarislowsky and Lloyd Carr-Harris foundations for their generous support.

\section{References}

Bernabé A, Gómez MA, Seva J, Serrano J, Sánchez J \& Navarro JA 2001 Light and ultrastructural immunocytochemical study of prolactin cells in ovine adenohypophysis. Influence of lactation and weaning. Cells, Tissues, Organs 168 264-271. (doi:10.1159/000047843)

Bjørkøy G, Lamark T, Brech A, Outzen H, Perander M, Øvervatn A, Stenmark H \& Johansen T 2005 p62/SQSTM1 forms protein aggregates degraded by autophagy and has a protective effect on huntingtininduced cell death. Journal of Cell Biology 171 603-614. (doi:10.1083/ jcb.200507002)

Bollheimer LC, Skelly RH, Chester MW, McGarry JD \& Rhodes CJ 1998 Chronic exposure to free fatty acid reduces pancreatic $\beta$ cell insulin content by increasing basal insulin secretion that is not compensated for by a corresponding increase in proinsulin biosynthesis translation. Journal of Clinical Investigation 101 1094-1101. (doi:10.1172/JCI420)

Bulling A, Berg FD, Berg U, Duffy DM, Stouffer RL, Ojeda SR, Gratzl M \& Mayerhofer A 2000 Identification of an ovarian voltage-activated $\mathrm{Na}+$-channel type: hints to involvement in luteolysis. Molecular Endocrinology 14 1064-1074. (doi:10.1210/mend.14.7.0481)

Carbone MC, Tatone C, Delle Monache S, Marci R, Caserta D, Colonna R \& Amicarelli F 2003 Antioxidant enzymatic defences in human follicular fluid: characterization and age-dependent changes. Molecular Human Reproduction 9 639-643. (doi:10.1093/molehr/gag090)

Chertow BS, Buschmann RJ \& Henderson WJ 1975 Subcellular mechanisms of parathyroid hormone secretion: ultrastructural changes in response to calcium, vitamin A, vinblastine, and cytochalasin B. Laboratory Investigation 32 190-200.

Choi AM, Ryter SW \& Levine B 2013 Autophagy in human health and disease. New England Journal of Medicine 368 651-662. (doi:10.1056/ NEJMra1205406)

Codogno P \& Meijer AJ 2005 Autophagy and signaling: their role in cell survival and cell death. Cell Death and Differentiation 12 1509-1518. (doi:10.1038/sj.cdd.4401751)

Cuervo AM, Bergamini E, Brunk UT, Dröge W, Ffrench M \& Terman A 2005 Autophagy and aging: the importance of maintaining "clean" cells. Autophagy 1 131-140. (doi:10.4161/auto.1.3.2017) http://jme.endocrinology-journals.org DOI: 10.1530/JME-13-0241 (c) 2014 Society for Endocrinology Printed in Great Britain 
Del Canto F, Sierralta W, Kohen P, Muñoz A, Strauss JF \& Devoto L 2007 Features of natural and gonadotropin-releasing hormone antagonistinduced corpus luteum regression and effects of in vivo human chorionic gonadotropin. Journal of Clinical Endocrinology and Metabolism 92 4436-4443. (doi:10.1210/jc.2007-0125)

Diemer T, Allen JA, Hales KH \& Hales DB 2003 Reactive oxygen disrupts mitochondria in MA-10 tumor Leydig cells and inhibits steroidogenic acute regulatory (StAR) protein and steroidogenesis. Endocrinology 144 2882-2891. (doi:10.1210/en.2002-0090)

Duerrschmidt N, Zabirnyk O, Nowicki M, Ricken A, Hmeidan FA, Blumenauer V, Borlak J \& Spanel-Borowski K 2006 Lectin-like oxidized low-density lipoprotein receptor-1-mediated autophagy in human granulosa cells as an alternative of programmed cell death. Endocrinology 147 3851-3860. (doi:10.1210/en.2006-0088)

de Duve C 1969 The lysosome in retrospect. Lysosomes in Biology and Pathology 1 3-40.

Ebato C, Uchida T, Arakawa M, Komatsu M, Ueno T, Komiya K, Azuma K, Hirose T, Tanaka K, Kominami E etal. 2008 Autophagy is important in islet homeostasis and compensatory increase of $\beta$ cell mass in response to highfat diet. Cell Metabolism 8 325-332. (doi:10.1016/j.cmet.2008.08.009)

Eid N, Shibata MA, Ito Y, Kusakabe K, Hammad H \& Otsuki Y 2002 Involvement of Fas system and active caspases in apoptotic signalling in testicular germ cells of ethanol-treated rats. International Journal of Andrology 25 159-167. (doi:10.1046/j.1365-2605.2002.00341.x)

Eid N, Ito Y \& Otsuki Y 2012 Enhanced mitophagy in Sertoli cells of ethanol-treated rats: morphological evidence and clinical relevance. Journal of Molecular Histology 43 71-80. (doi:10.1007/s10735-0119372-0)

Farquhar MG 1969 Lysosome function in regulating secretion: disposal of secretory granules in cells of the anterior pituitary gland. In Lysosomes in Biology and Pathology, vol 2, pp 462-482. Eds JT Jingle \& HB Fell. Amsterdam: North-Holland Publ.

Farquhar MG 1971 Processing of secretory products by cells of the anterior pituitary gland. Memoirs of the Society for Endocrinology 19 79-122.

Farquhar MG 1977 Secretion and crinophagy in prolactin cells. Advances in Experimental Medicine and Biology 80 37-94. (doi:10.1007/978-1-46156675-5_3)

Gannon AM, Stämpfli MR \& Foster WG 2013 Cigarette smoke exposure elicits increased autophagy and dysregulation of mitochondrial dynamics in murine granulosa cells. Biology of Reproduction $\mathbf{8 8} 63$. (doi:10.1095/biolreprod.112.106617)

Gawriluk TR, Hale AN, Flaws JA, Dillon CP, Green DR \& Rucker EB 2011 Autophagy is a cell survival program for female germ cells in the murine ovary. Reproduction 141 759-765. (doi:10.1530/REP-10-0489)

Gaytán M, Morales C, Sánchez-Criado JE \& Gaytán F 2008 Immunolocalization of beclin 1, a bcl-2-binding, autophagy-related protein, in the human ovary: possible relation to life span of corpus luteum. Cell and Tissue Research 331 509-517. (doi:10.1007/s00441-007-0531-2)

Grasso D, Sacchetti ML, Bruno L, Lo Ré A, Gonzalez CD \& Vaccaro MI 2009 Autophagy and VMP1 expression are early cellular events in experimental diabetes. Pancreatology 9 81-88. (doi:10.1159/000178878)

Habener JF, Kemper B \& Potts JT Jr 1975 Calcium-dependent intracellular degradation of parathyroid hormone: a possible mechanism for the regulation of hormone stores. Endocrinology 97 431-441. (doi:10.1210/ endo-97-2-431)

Halban PA 1991 Structural domains and molecular lifestyles of insulin and its precursors in the pancreatic $\beta$ cell. Diabetologia 34 767-778. (doi:10.1007/BF00408349)

Halban PA \& Wollheim CB 1980 Intracellular degradation of insulin stores by rat pancreatic islets in vitro. An alternative pathway for homeostasis of pancreatic insulin content. Journal of Biological Chemistry 255 6003-6006.

Hara T, Nakamura K, Matsui M, Yamamoto A, Nakahara Y, SuzukiMigishima R, Yokoyama M, Mishima K, Saito I, Okano H et al. 2006 Suppression of basal autophagy in neural cells causes neurodegenerative disease in mice. Nature 441 885-889. (doi:10.1038/nature04724)
Hartley T, Brumell J \& Volchuk A 2009 Emerging roles for the ubiquitin-proteasome system and autophagy in pancreatic $\beta$-cells. American Journal of Physiology. Endocrinology and Metabolism 296 E1-E10. (doi:10.1152/ajpendo.90538.2008)

Holtzman E \& Dominitz R 1968 Cytochemical studies of lysosomes, Golgi apparatus and endoplasmic reticulum in secretion and protein uptake by adrenal medulla cells of the rat. Journal of Histochemistry and Cytochemistry 16 320-336. (doi:10.1177/16.5.320)

Jung HS \& Lee MS 2009 Macroautophagy in homeostasis of pancreatic $\beta$-cell. Autophagy 5 241-243. (doi:10.4161/auto.5.2.7518)

Jung HS, Chung KW, Won Kim J, Kim J, Komatsu M, Tanaka K, Nguyen YH, Kang TM, Yoon KH, Kim JW et al. 2008 Loss of autophagy diminishes pancreatic $\beta$ cell mass and function with resultant hyperglycemia. Cell Metabolism 8 318-324. (doi:10.1016/j.cmet.2008.08.013)

Kaniuk NA, Kiraly M, Bates H, Vranic M, Volchuk A \& Brumell JH 2007 Ubiquitinated-protein aggregates form in pancreatic $\beta$-cells during diabetes-induced oxidative stress and are regulated by autophagy. Diabetes 56 930-939. (doi:10.2337/db06-1160)

Kimura S, Noda T \& Yoshimori T 2007 Dissection of the autophagosome maturation process by a novel reporter protein, tandem fluorescenttagged LC3. Autophagy 3 452-460.

Klionsky DJ 2005 The molecular machinery of autophagy: unanswered questions. Journal of Cell Science 118 7-18. (doi:10.1242/jcs.01620)

Klionsky DJ, Cuervo AM, Dunn WA Jr, Levine B, van der Klei IJ \& Seglen PO 2007 How shall I eat thee? Autophagy 3 413-416.

Klionsky DJ, Abdalla FC, Abeliovich H, Abraham RT, Acevedo-Arozena A, Adeli K, Agholme L, Agnello M, Agostinis P, Aguirre-Ghiso JA et al. 2012 Guidelines for the use and interpretation of assays for monitoring autophagy. Autophagy 8 445-544. (doi:10.4161/auto.19496)

Kuriakose NR, Reifel CW, Bendavan M, Elce JS \& Shin SH 1989 Prolactin crinophagy is induced in the estrogen-stimulated male rat pituitary. Histochemistry 92 499-503. (doi:10.1007/BF00524761)

Landström AS 1987 A role for crinophagy in pancreatic islet B-cells: minireview based on a doctoral thesis. Upsala Journal of Medical Sciences 92 99-113. (doi:10.3109/03009738709178684)

Las G, Serada SB, Wikstrom JD, Twig G \& Shirihai OS 2011 Fatty acids suppress autophagic turnover in $\beta$-cells. Journal of Biological Chemistry 286 42534-42544. (doi:10.1074/jbc.M111.242412)

Levine B \& Klionsky DJ 2004 Development by self-digestion: molecular mechanisms and biological functions of autophagy. Developmental Cell 6 463-477. (doi:10.1016/S1534-5807(04)00099-1)

Levine B \& Kroemer G 2008 Autophagy in the pathogenesis of disease. Cell 132 27-42. (doi:10.1016/j.cell.2007.12.018)

Li WR, Chen L, Chang ZJ, Xin H, Liu T, Zhang YQ, Li GY, Zhou F, Gong YQ Gao ZZ et al. 2011 Autophagic deficiency is related to steroidogenic decline in aged rat Leydig cells. Asian Journal of Andrology 13 881-888. (doi:10.1038/aja.2011.85)

Lupi R, Dotta F, Marselli L, Del Guerra S, Masini M, Santangelo C, Patané G, Boggi U, Piro S, Anello M et al. 2002 Prolonged exposure to free fatty acids has cytostatic and pro-apoptotic effects on human pancreatic islets evidence that $\beta$-cell death is caspase mediated, partially dependent on ceramide pathway, and bcl-2 regulated. Diabetes $\mathbf{5 1}$ 1437-1442. (doi:10.2337/diabetes.51.5.1437)

Marsh BJ, Soden C, Alarcón C, Wicksteed BL, Yaekura K, Costin AJ, Morgan GP \& Rhodes CJ 2007 Regulated autophagy controls hormone content in secretory-deficient pancreatic endocrine $\beta$-cells. Molecular Endocrinology 21 2255-2269. (doi:10.1210/me.2007-0077)

Marzella L, Ahlberg J \& Glaumann H 1981 Autophagy, heterophagy, microautophagy and crinophagy as the means for intracellular degradation. Virchows Archiv. B, Cell Pathology Including Molecular Pathology 36 219-234. (doi:10.1007/BF02912068)

Masini M, Bugliani M, Lupi R, Del Guerra S, Boggi U, Filipponi F, Marselli L, Masiello P \& Marchetti P 2009 Autophagy in human type 2 diabetes pancreatic $\beta$ cells. Diabetologia 52 1083-1086. (doi:10.1007/s00125009-1347-2) 
Mathew R, Karantza-Wadsworth V \& White E 2007 Role of autophagy in cancer. Nature Reviews. Cancer 7 961-967. (doi:10.1038/nrc2254)

McGarry JD \& Dobbins RL 1999 Fatty acids, lipotoxicity and insulin secretion. Diabetologia 42 128-138. (doi:10.1007/s001250051130)

Mizushima N 2007 Autophagy: process and function. Genes and Development 21 2861-2873. (doi:10.1101/gad.1599207)

Mizushima N \& Hara T 2006 Intracellular quality control by autophagy: how does autophagy prevent neurodegeneration? Autophagy 2 302-304.

Mizushima N, Levine B, Cuervo AM \& Klionsky DJ 2008 Autophagy fights disease through cellular self-digestion. Nature 451 1069-1075. (doi:10.1038/nature06639)

Mizushima N, Yoshimori T \& Levine B 2010 Methods in mammalian autophagy research. Cell 140 313-326. (doi:10.1016/j.cell.2010.01.028)

Moi VD, Bácsy E, Gaál G \& Rappay G 1984 Lysosomal enzyme activities in hypo- and hypersecretory anterior pituitary cells. A combined immunocytochemical and enzyme cytochemical study. Histochemistry 81 79-85. (doi:10.1007/BF00495405)

Müller J, Pfeifer U \& Dämmrich J 1987 Inhibited autophagic degradation during ACTH-stimulated growth of rat adrenal zona fasciculata. Virchows Archiv. B, Cell Pathology Including Molecular Pathology 52 429-441. (doi:10.1007/BF02889983)

Mutlu-Türkoğlu Ü, Öztezcan S, Telci A, Orhan Y, Aykac-Toker G, Sıvas A \& Uysal M 2003 An increase in lipoprotein oxidation and endogenous lipid peroxides in serum of obese women. Clinical and Experimental Medicine 2 171-174. (doi:10.1007/s102380300002)

Pfeifer U 1979 Inhibited autophagic degradation of cytoplasm during compensatory growth of liver cells after partial hepatectomy. Virchows Archiv. B, Cell Pathology Including Molecular Pathology 30 313-333.

Poole MC, Mahesh VB \& Costoff A 1981 Morphometric analysis of the autophagic and crinophagic lysosomal systems in mammotropes throughout the estrous cycle of the rat. Cell and Tissue Research 220 131-137. (doi:10.1007/BF00209972)

Ravikumar B, Sarkar S, Davies JE, Futter M, Garcia-Arencibia M, Green-Thompson ZW, Jimenez-Sanchez M, Korolchuk VI, Lichtenberg M, Luo S et al. 2010 Regulation of mammalian autophagy in physiology and pathophysiology. Physiological Reviews 90 1383-1435. (doi:10.1152/physrev.00030.2009)

Sandberg M \& Borg LA 2007 Steroid effects on intracellular degradation of insulin and crinophagy in isolated pancreatic islets. Molecular and Cellular Endocrinology 277 35-41. (doi:10.1016/j.mce.2007.07.007)

Schnell AH, Swenne I \& Borg LA 1988 Lysosomes and pancreatic islet function. A quantitative estimation of autophagy in the mouse pancreatic B-cell. Cell and Tissue Research 252 9-15. (doi:10.1007/ BF00213820)

Serke H, Vilser C, Nowicki M, Hmeidan FA, Blumenauer V, Hummitzsch K, Lösche A \& Spanel-Borowski K 2009 Granulosa cell subtypes respond by autophagy or cell death to oxLDL-dependent activation of the oxidized lipoprotein receptor 1 and toll-like 4 receptor. Autophagy 5 991-1003. (doi:10.4161/auto.5.7.9507)

Sinha RA, You SH, Zhou J, Siddique MM, Bay BH, Zhu X, Privalsky ML, Cheng SY, Stevens RD, Summers SA et al. 2012 Thyroid hormone stimulates hepatic lipid catabolism via activation of autophagy. Journal of Clinical Investigation 122 2428-2438. (doi:10.1172/JCI60580)

Sirek AM, Horvath E, Ezrin C \& Kovacs K 1976 Effect of starvation on pituitary growth hormone cells and blood growth hormone and prolactin levels in the rat. Annals of Nutrition \& Metabolism 20 67-75. (doi:10.1159/000175688)

Smith RE \& Farquhar MG 1966 Lysosome function in the regulation of the secretory process in cells of the anterior pituitary gland. Journal of Cell Biology 31 319-347. (doi:10.1083/jcb.31.2.319)

Tallóczy Z, Jiang W, Virgin HW, Leib DA, Scheuner D, Kaufman RJ, Eskelinen EL \& Levine B 2002 Regulation of starvation- and virus-induced autophagy by the eIF $2 \alpha$ kinase signaling pathway. PNAS 99 190-195. (doi:10.1073/pnas.012485299)

Tang XM 1988 The autophagic activity of Leydig cells in the normal rat testes. Acta Biologiae Experimentalis Sinica 21 119-129.

Tanida I 2011 Autophagy basics. Microbiology and Immunology 55 1-11. (doi:10.1111/j.1348-0421.2010.00271.x)

Tatone C, Carbone MC, Falone S, Aimola P, Giardinelli A, Caserta D, Marci R, Pandolfi A, Ragnelli AM \& Amicarelli F 2006 Age-dependent changes in the expression of superoxide dismutases and catalase are associated with ultrastructural modifications in human granulosa cells. Molecular Human Reproduction 12 655-660. (doi:10.1093/molehr/ gal080)

Tatone C, Amicarelli F, Carbone MC, Monteleone P, Caserta D, Marci R, Artini PG, Piomboni P \& Focarelli R 2008 Cellular and molecular aspects of ovarian follicle ageing. Human Reproduction Update $\mathbf{1 4}$ 131-142. (doi:10.1093/humupd/dmm048)

Trifaro J 1977 Common mechanisms of hormone secretion. Annual Review of Pharmacology and Toxicology 17 27-47. (doi:10.1146/annurev.pa.17. 040177.000331)

Twig G, Elorza A, Molina AJ, Mohamed H, Wikstrom JD, Walzer G, Stiles L, Haigh SE, Katz S, Las G et al. 2008 Fission and selective fusion govern mitochondrial segregation and elimination by autophagy. EMBO Journal 27 433-446. (doi:10.1038/sj.emboj.7601963)

Vilser C, Hueller H, Nowicki M, Hmeidan FA, Blumenauer V \& Spanel-Borowski K 2010 The variable expression of lectin-like oxidized low-density lipoprotein receptor (LOX-1) and signs of autophagy and apoptosis in freshly harvested human granulosa cells depend on gonadotropin dose, age, and body weight. Fertility and Sterility 93 2706-2715. (doi:10.1016/j.fertnstert.2009.02.038)

Yang Z \& Klionsky DJ 2009 An overview of the molecular mechanism of autophagy. Current Topics in Microbiology and Immunology 335 1-32. (doi:10.1007/978-3-642-00302-8_1)

Yang Z \& Klionsky DJ 2010 Mammalian autophagy: core molecular machinery and signaling regulation. Current Opinion in Cell Biology 22 124-131. (doi:10.1016/j.ceb.2009.11.014)

Yang Z, Chee CE, Huang S \& Sinicrope FA 2011 The role of autophagy in cancer: therapeutic implications. Molecular Cancer Therapeutics 10 1533-1541. (doi:10.1158/1535-7163.MCT-11-0047)

Yen PM 2001 Physiological and molecular basis of thyroid hormone action. Physiological Reviews 81 1097-1142.

Yi J \& Tang XM 1995 Functional implication of autophagy in steroidsecreting cells of the rat. Anatomical Record 242 137-146. (doi:10.1002/ ar.1092420202)

Zhou YP \& Grill VE 1994 Long-term exposure of rat pancreatic islets to fatty acids inhibits glucose-induced insulin secretion and biosynthesis through a glucose fatty acid cycle. Journal of Clinical Investigation 93 870-876. (doi:10.1172/JCI117042)

Zirkin BR \& Chen H 2000 Regulation of Leydig cell steroidogenic function during aging. Biology of Reproduction 63 977-981. (doi:10.1095/ biolreprod63.4.977)

Received in final form 19 December 2013

Accepted 8 January 2014 http://jme.endocrinology-journals.org DOI: 10.1530/JME-13-0241
(C) 2014 Society for Endocrinology Printed in Great Britain 